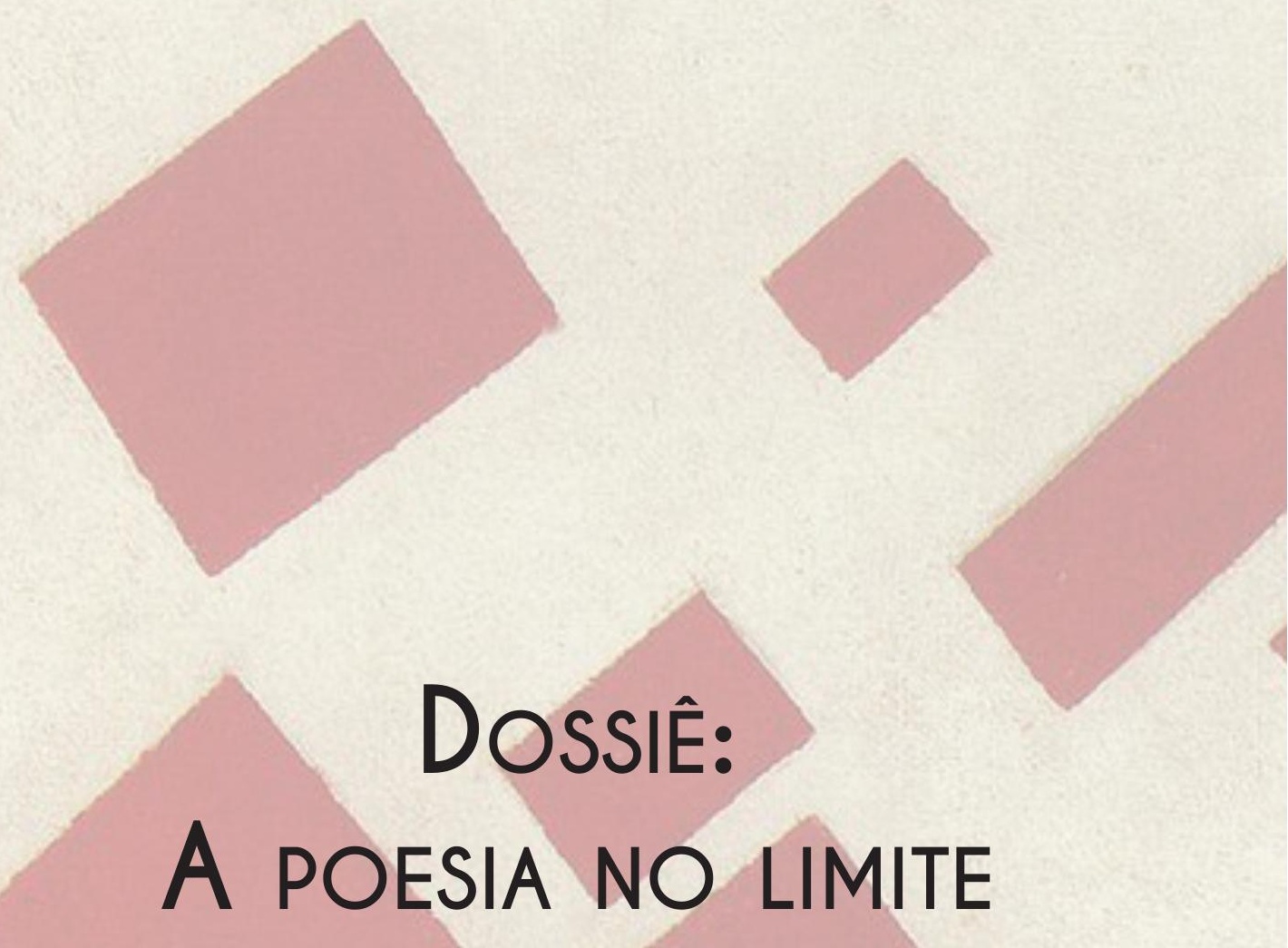




\title{
MARTHYA DE ABDEL HAMID, SEGUNDO ALBERTO PIMENTA - DA TERRA E DO CORPO QUEIMADOS, MAS DO CORAÇÃO REGENDO A VIDA
}

\author{
MARTHYA DE ABDEL HAMID, SEGUNDO ALBERTO \\ PIMENTA - ABOUT THE EARTH AND THE BODY - \\ SCORCHED; BUT ALSO ABOUT THE HEART RULING \\ LIFE
}

Ana LUISA AmaraL

Resumo: Partindo da noção de orientalismo, desenvolvida em 1978 por Edward Said, e retomada depois no seu Cultura e Imperialismo (1993), discutirei os conceitos de "vida precária" e de "materialidade do corpo", avançados por Judith Butler, aplicando-os a uma leitura do poema Marthyia de Abdel Hamid (2005), de Alberto Pimenta. Tentarei mostrar como nesse poema se denuncia a perpetuação da construção do "outro", não ocidental, como estranho ameaçador, e como a poesia pode, na sua condição de utopia fazível, contribuir para que "o fumo de uma terra queimada / não dur[e] sempre".

Palavras-chave: poesia portuguesa, Alberto Pimenta, orientalismo, "outridade", Edward Said, Judith Butler

Abstract: Departing from the concept of orientalism, developed in 1978 by Edward Said, and later expanded in his book Culture and Imperialism (1993), I will discuss the topics of "precarious life" and "materiality of the body", proposed by Judith Butler, and apply them to a poem by Alberto Pimenta called Marthyia de Abdel Hamid (2005). I will try to show how this poem denounces the social construction of the "other" - the nonWestern - as a menacing stranger and how poetry can, through its condition of feasible utopia, prove that "the smolder left from a scorched land / does not last forever".

Keywords: portuguese poetry, Alberto Pimenta, Orientalism, "otherness", Edward Said, Judith Butler

* Professora da Faculdade de Letras da Universidade do Porto, Portugal, onde integra também a direção do Instituto de Literatura Comparada Margarida Losa. 
Descasca hoje uma batata em meu nome sabendo que não Ihe chamarei nunca tubérculo. Seja esse o teu primeiro exercício de igualdade entre os humanos.

Maria Velho da Costa, Casas Pardas

o seu clássico Orientalism, publicado pela primeira vez em 1978, Edward Said mostrou como foi sendo criada uma dicotomia entre a realidade dos territórios a Leste do Ocidente e as representações estereotipadas de "Oriente" (ora exóticas, ora românticas, ora sinónimo de barbárie e subdesenvolvimento). Said sublinharia que nem o conceito de 'Oriente' nem o conceito de 'Ocidente' têm qualquer estabilidade ontológica: ambos são feitos de esforço humano, parcialmente afirmando, parcialmente identificando, parcialmente obliterando o Outro - ficções, afinal, que se emprestam à manipulação e à paixão colectiva. Na reedição do livro em 2003 (o ano da sua morte), Edward Said comporia para Orientalism um prefácio onde integrava já reflexões em torno da invasão do Iraque e da demonização dos povos árabes pela administração Bush. "O que os nossos governantes e os seus lacaios intelectuais parecem incapazes de compreender", escrevia Said nesse prefácio, "é que a história não pode ser limpa como se limpa um quadro da escola, limpa de forma a que 'nós' possamos inscrever nele o nosso futuro e impor as nossas formas de viver a esses povos 'menores"' (SAID, 2003, p. xiii). ${ }^{1}$ Objectos de preconceito e de racismo, o Médio Oriente e a Ásia eram vistos como não tendo consciência da sua própria história e cultura, por isso o Ocidente Ihes criou, em gesto imperialista, uma cultura e uma história que preenchesse esse vazio. "É muito comum", continuava Said nesse prefácio, "ouvir gente importante de Washington a falar de mudar o mapa do Médio Oriente, como se as sociedades antigas e os povos diversos pudessem ser agitados, como se fossem amendoins dentro de um frasco. Mas isto aconteceu muitas vezes com o 'Oriente', essa construção semi-mítica que, desde a invasão do Egipto por Napoleão no século XVIII, foi feita e refeita vezes sem conta pelo poder que sobre ela actuou através de uma forma conveniente de conhecimento, declarando que esta é a natureza do Oriente, e que só nos resta lidar com ela em conformidade" (ibid.).

A guerra do Iraque (ou Segunda Guerra do Golfo, como ficou também conhecida), iniciada unilateralmente e de forma ilegal com a invasão do país, em 2003,

\footnotetext{
${ }^{1}$ Excepto quando indicado, todas as traduções são da minha responsabilidade.
} 
pelos Estados Unidos da América e pela Inglaterra, sob o pretexto de que o governo de Sadam Hussein detinha a posse de armas químicas, provocaria quase meio milhão de mortos, quatro milhões de feridos e perto de cinco milhões de refugiados de guerra, envolvendo jogos de poder que foram cruzando o capital e a política, empresas ligadas ao executivo norte-americano e a forças políticas conservadoras, que destruíram grande parte das infra-estruturas iraquianas, para depois lucrarem com a sua reconstrução. Os norte-americanos, e o resto do mundo, veriam, no rescaldo também do 11 de Setembro, o governo de George Bush passar, impune, leis como o Patriot Act, ou defender a necessidade de criar (ou reaproveitar) campos de detenção como os de Abu-Grahib ou Guantánamo, onde se interrogavam e se detinham "terroristas" e "muçulmanos perigosos", sem necessidade de julgamentos prévios. Em 2002, no seu discurso sobre o Estado da União, Bush havia falado do "eixo do mal", apostado, dizia ele, em ameaçar a paz do mundo, e em 2005, Dick Cheney, então vice-presidente dos Estados Unidos, descrevia assim o tratamento dado aos prisioneiros de Guantánamo: "Não há nação no mundo que trate aqueles que estão determinados a matar americanos da mesma forma que nós tratamos esta gente. Eles vivem nos trópicos. São bem alimentados. Têm tudo o que querem".

2005 seria justamente o ano da publicação do livro de Alberto Pimenta, Marthya de Abdel Hamid, onde se pode ler, em clara denúncia da invasão do Iraque:

Querem contar eles

A história

Toda

Mas a história

Não é só sua

E da outra metade do bando (PIMENTA, 2005, p. 32).

Poema dividido em 35 partes, ou texto composto por 35 poemas (opção que aqui seguirei, por comodidade de exposição), o livro empresta-se da figura de Abdul Hamid (1848-1918), poeta e tradutor e o último sultão a exercer poder efectivo no império Otomano, que havia emergido em 1299, tendo por centro Constantinopla, e que, no seu auge, compreendia a Anatólia, parte do norte de África e do sudeste europeu e o Médio Oriente, e cujos territórios viriam a ser 
desmembrados em 1922, depois da Primeira Grande Guerra, em parte devido às intervenções francesa e britânica. Um novo xadrez político e sócio-geográfico se haveria de desenhar, após essa que foi o início da guerra moderna, tão bem representada por T.S. Eliot em The Waste Land, esse grande poema do modernismo ocidental, publicado em 1922, que convocaria também o Oriente, ambos os espaços unidos pelos motivos da fragmentação e da metamorfose: "Eu não pensava que a morte havia aniquilado tantos. [...] / O cadáver que plantaste o ano passado no jardim / Já começou a dar rebentos? Será que dá flor este ano?" (ELIOT, 1999,p. 23).

A voz que fala os poemas de Alberto Pimenta é a do governante/poeta Abdul Hamid, que, para além de prantear o presente, relembra um passado mítico de grandeza, em que as marcas topográficas evocadas se confundem com as marcas simbólicas da memória dos espaços e dos tempos que nos fizeram a todos civilização - por isso as referências que vão surgindo ao longo dos poemas não dizem só respeito ao Iraque, mas espalham-se pelas "montanhas de Zagros" (hoje Sudoeste do Irão), pela "cidade de Dasmasco" (hoje capital da Síria), pela "cidadela de Alepo" e pelas "azenhas milenares de Hama" (no norte e no centro da Síria), pelo "deserto que rodeia Raqqa" (também na Síria, a parte ocidental da região historicamente conhecida como Al-Jazira), pelas águas do rio Oronte (que corre nos territórios do Líbano, da Síria e da Turquia).

"Marthya" significa, em persa, "elegia", ou lamento, geralmente por alguém morto. Aqui, é a elegia pela agonia de um povo, a qual, necessariamente, nos implica a todos, e ao nosso próprio passado europeu de imperialismo e colonização, ainda que nos possa ser de desconforto esse reconhecimento. E não seria por acaso que, na altura da publicação, o livro de Alberto Pimenta, lançado na Mesquita de Lisboa, veria a sua leitura boicotada em várias livrarias de Portugal (país que não enviou soldados para o Iraque, mas que teve poetas como Vasco Graça Moura a apoiar abertamente a sua invasão).

Em gesto em que se assume como o de uma espécie de discípulo de um novo evangelho, não cristão, mas muçulmano, Pimenta dará ao seu livro um subtítulo: "segundo Alberto Pimenta": Marthya de Abdel Hamid, segundo Alberto Pimenta. O poeta ensaia-se ele mesmo voz da voz de Abdel Hamid, recriando-a. Mais do que isso, Pimenta "traduz" essa voz para a nossa língua. Esse processo de tradução aplicado aqui à poesia pode ser aproximado do sentido que lhe dá Saadi Simawe, o organizador de Iraqi Poetry Today: "A globalização do capital 
ameaça extinguir o espírito de cada cultura, mas uma mudança positiva surgiu com este movimento, lançando luz sobre a importância da tradução. A tradução pode, claro, ser vista como um instrumento que facilita a globalização do capital, assim contribuindo para o enfraquecimento das culturas, mas quando a poesia é traduzida, ela contraria estes efeitos" $(2003, p .5)$. Não se trata aqui, portanto, de traduzir Abdel Hamid no sentido literal, mas de, ao assumir o tom lírico da poesia árabe dos divãs (tornando o texto anti-imperialista em conteúdo e forma), adoptar, como diz Pimenta em entrevista, "o [...] tom [de Abdel Hamid] repassado da presença amável e insubstituível da natureza", "de dentro para fora", que só assim seria credível, e não "panfletário", ou "declamatório em diatribe, à maneira ocidental (de fora para dentro)" (PIMENTA, 2010).

Em 2003, o ano da invasão do Iraque, milhares de obras de arte e artefactos arqueológicos pertencentes às civilização suméria e a outros períodos da história da Mesopotâmia desapareceram de Bagdad. Enquanto se protegiam poços de petróleo, os museus eram saqueados e o seu recheio pilhado ou destruído. Uma curadora do Museu Nacional do Iraque, em Bagdad, Nabhal Amin, declararia: "Bastava que os norte-americanos tivessem usado um tanque e dois soldados para que isto não se tivesse passado. Acuso as tropas americanas de serem responsáveis pelo que aconteceu" (BBC NEWS, 2003).

Há mil anos

Nas bibliotecas de Bagdad

Havia mais livros

Que num milhar

De conventos dos cristãos.

O museu,

Ainda há pouco,

Guardava mais memória da Mesopotâmia

[...]

Que a recolhida

No resto do mundo,

Como despojo

De todas as pilhagens. (PIMENTA, 2005,p. 24-5). 
Assim fala a voz de Abdel Hamid, para concluir, em seca ironia: "Não é nenhum apaixonante / Drama histórico, / É parte da história do roubo / Que sustenta o Ocidente" (id, ibid). "O crime do século" - assim foi chamado este acto de barbárie contra a história humana, que não teve por detrás somente a negligência ou a ganância, mas teve também por objectivo a humilhação de um povo, a destruição do "outro" e dos traços de uma das civilizações mais antigas do mundo, através da destruição da sua memória.

Escrever que "o fumo de uma terra queimada / Não dura sempre" (PIMENTA, 2005 ,p. 12), ou falar do invasor como aquele que, apesar de tudo, "não conseguirá / Fazer [do coração] / Uma esponja / Permeável à peste / Que [...] espalha / À tona suave / Da água da vida "(id: 10) é encontrar na poesia um qualquer ponto de resistência à ordem dos tiranos, ligada à esterilidade e à tristeza, aquela que, como diz Gilles Deleuze lendo Espinosa, proíbe a expansão das capacidades individuais e a sua expansão, por sua vez, à colectividade $(2003, \text { p. } 30)^{2}$. É denunciar que a ordem dos tiranos só gera violência, por isso precisam eles de se "ampara[r] / A uma espingarda, / Como os cegos / A uma bengala" (PIMENTA, 2005, p. 13). E é lutar ferozmente contra a ideia propagada pelo discurso oficial estadounidense de que, até ao escândalo de Abu-Grahib, em 2004, a atrocidade e a violência cabiam só a Hassam Hussein e a grupos iraquianos, apagando-se os rastos de violência e atrocidade das forças da coalização, substituindo-os pela propagação de fotografias e de vídeos mandatados pelo Departamento de Defesa norte-americano e assim se criando molduras visuais que pudessem justificar uma moldura social, informada pelo político e pelo normativo, onde certos corpos pudessem (e devessem) ser mais dispensáveis do que outros (BUTLER,p. 2009).

Talvez por isso o sentido da visão, como tentarei mostrar mais à frente, seja um tópico tão importante neste livro de Alberto Pimenta, podendo funcionar como antídoto a essas imagens politicamente induzidas - uma visão, no caso de Pimenta, que muitas vezes se faz por dentro do próprio coração, ou seja, através da poesia. Talvez por esta razão haja momentos em que neste livro ecoa o famoso poema de Bertolt Brecht, dos Svendborger Gedichte (1939), tão actual

\footnotetext{
${ }^{2}$ De referir que o livro de Deleuze Spinoza: Philosophie Pratique surge pela primeira vez editado pela Presses Universitaires de France, em 1970, sendo depois reeditado (em versão aumentada) pela Editions Minuit em 1981 e em 2003. A edição que aqui usei foi a de 2003.
} 
também nos nossos tempos: "Nos tempos escuros / Haverá também canções? Sim, haverá também canções / Sobre os tempos escuros" (1979,p. 320). Daí que se ofereça espaço, ao longo dos 35 poemas, a um texto que, ainda que entrecruzado com imagens de violência, é um belíssimo poema de amor:

Para voltar

A ver-te

Um só instante,

A ti,

Que és mais bela que a lua,

Antes que a manhã recolha

As estrelas

Uma a uma

E as guarde

Do outro lado do céu

[...]

Vou passar

Do lado de fora

Da parede

Perfurada

Pelas balas:

Passa-me um lenço

De seda

Com o teu perfume.

Marca-o com o segredo

Dos teus lábios. (PIMENTA 2005,p. 51):

A interrupção não do lírico pelo político, ${ }^{3}$ mas, neste caso, do político pelo lírico, que irrompe e suspende o cenário de devastação provocado pela guer-

\footnotetext{
${ }^{3}$ Recorro aqui ao conceito de "interrupção poética", tal como ele surge formulado por Maria Irene Ramalho em ensaios como "Interrupção poética: Um conceito pessoano para a lírica moderna" (2000), ou no seu livro Poetas do Atlântico: Fernando Pessoa e o modernismo angloamericano (2007), publicado pela primeira vez, em versão inglesa, nos Estados Unidos, em 2003,
} 
ra, poderia ser, de resto, comparado a uma belíssima sequência de poemas de Adrienne Rich, uma das maiores vozes da poesia norte-americana contemporânea, ensaísta, lésbica e feminista, cuja integridade e desassombro ficaram bem demonstrados na sua recusa em aceitar, em 1997, a "National Medal for the Arts" defendendo que "a arte - no meu caso, a arte da poesia - nada significa se decorar somente a mesa de jantar do poder que a tem refém" (RICH, 1997). A sequência de Rich chama-se "Twenty-One Love Poems" (RICH, 1978); todos os poemas são numerados, excepto um, a meio da sequência, intitulado "The Floating Poem, Unnumbered" (iibid., p. 32). Como fazem notar Maria Irene Ramalho e Mónica Andrade, esse "poema flutuante, sem número, [...] é um verdadeiro hino ao prazer sexual lésbico, reivindicado na sua totalidade plena [...]", exibindo um registo eminente e declaradamente amoroso e erótico, quando comparado com os outros, que cruzam o amor com gestos do quotidiano e questões ligadas à cidadania (RAMALHO e ANDRADE, 2008,p. 21)

Mas os dois movimentos de interrupção coabitam no livro, assim demonstrando a inscrição da poesia no mundo, sabendo-se que da nossa história fará parte também a transmissão e a integração de novas maneiras de o encarar, ao mundo, e àquilo que a ele pertence, dessacralizado porque, como dizia Said, solicitando a sua atenção (SAID, 1983, p. 40), ou seja, o texto literário. Essa coabitação dos dois planos, ou essa inscrição, encontramo-la em poemas de Amarthya de Abdel Hamid, como esse que o poeta acusa os invasores ocidentais de terem perdido o contacto com a natureza das coisas, vendidos que foram "ao dinheiro, sempre obscuro, e ao enriquecimento, sempre ilícito": "Já há séculos / Que não têm alma", lê-se no poema 5. "Venderam-na / E continuam a vendê-la: / Têm compradores / Entre os que trazem os olhos / Vendados pela imaginação" (PIMENTA, 2005,p. 16). E eu penso de novo em Adrienne Rich e num seu poema de 1991, o ano da invasão do Kuwait e da Primeira Guerra do Golfo, um poema que fala de um lugar secreto, e de árvores, e de revoluções. "Que tempos são estes" [What kind of times are these], pergunta o poema de Rich no seu título, dispensando o sinal de pontuação (RICH, 1995,p. 3):

como Atlantic Poets: Fernando Pessoa's turn in anglo-american. Escreve Maria Irene Ramalho: “... é a interrupção, ao levar o político a romper com a imaginação unificadora do poeta, que é responsável pelo poético. [...] Dito de outro modo, o poético precisa da interrupção do político para se fundar e assim reclamar, intacto, o poder da língua" (2007,p. 249-250). 
Há um lugar entre duas filas de árvores onde a erva cresce monte acima e a velha estrada revolucionária se quebra em sombras perto de uma casa-abrigo abandonada pelos perseguidos que desapareceram nessas sombras.

Fui até lá apanhar cogumelos na borda do terror, mas não te enganes, isto não é um poema russo nem este é um lugar qualquer, é aqui, o nosso país cada vez mais perto da sua verdade e do seu terror, as suas formas próprias de fazer pessoas desaparecer.

Não te direi onde é este lugar, a malha escura dos bosques abrigando uma linha de luz despercebida encruzilhadas percorridas por fantasmas, o paraíso dos musgos: já sei quem o vai querer vender, comprar, fazer desaparecer.

Não te digo onde fica, então, porque te digo eu seja o que for? Porque tu ainda escutas, porque em tempos como estes ter-te aí a escutar, é necessário falar de árvores.

O lugar secreto de que fala o poema de Adrienne Rich situa-se nos Estados Unidos, o espaço que alberga um tempo passado repleto das memórias que formaram um povo dividido entre colonos e colonizados, os livres e os não livres, o tempo do horror da conquista, da expansão e da carnificina. Esse lugar secreto é ainda o lugar que alberga no tempo presente o desejo de liberdade a paredes meias com o imperialismo, a ambição e o desejo do lucro imediato e desmedido. Todavia, esse lugar é também o reduto utópico possível, convocando, lateralmente, a riqueza da poesia de outros lugares, na referência ao poema russo, tal como o 'tu' a quem o poema se dirige é o leitor e a leitora, mas igualmente a cidadã e o cidadão, seres cúmplices do mundo e do tempo e simultaneamente seus redentores, na comunhão da escuta e da importância que tem a poesia lírica como resistência. Talvez por isso é este um poema que, tal como os poemas de Marthya de Abdel Hamid (embora, geográfica e simbolicamente, a colocação das vozes de Rich e Pimenta se posicionem em pontos cardeais diversos), aponta o futuro como referência, alertando para a convivência da beleza e do horror. 
Uma cartografia a vários tempos, que não dispensa a ideia de outro, como mesmo, ainda que alheio.

Esta convocação do "estrangeiro", ou do "outro" e da estranheza de sermos e de encarnarmos nós mesmos o estranho e o diverso nunca deixou, nem nunca deixaria, de estar presente na poesia de Alberto Pimenta, a par da paródia e do humor cáustico. Sempre contundente e inconformada; sempre de acordo com uma visão da poesia que nada tem a ver com "algumas chamadas vanguardas que praticam a poesia dos falsos problemas, antes realizando uma poética em busca dos sentidos transformadores do que pode ser dito e pensado, aquela que detém a capacidade de nos recordar algo que estávamos proibidos de ver. [...] Um futuro esquecido, afinal” (RICH, 2009, p. 143). Por isso foi possível a Alberto Pimenta escrever textos corrosivos e de feroz mordacidade como, em Bestiário Lusitano, de 1980, aquele intitulado "A situação da ovelha", que termina assim:

A ovelha entrega o boletim dobrado em quatro

e por hábito pergunta: - Quanto é? /

- A nossa democracia assenta no voto gratuito -

diz o presidente da mesa. (PIMENTA, 1980, p. 26)

Por isso também lhe foi possível realizar a base de um "acto poético", fazendo explodir, como faz notar Maria Irene Ramalho, o conhecido soneto de Camões 'Transforma-se o amador na coisa amada', "para em seguida meticulosamente Ihe recolher as letras uma a uma, e fazer um outro. As duas letras, que de modo nenhum cabem no texto e por isso sobram servem de assinatura ao novo soneto: L(uís) C(amões)" (RAMALHO, JL, 2013); ou ainda escrever, em 1998, um curto, mas poderoso, poema:

Hoje sonhei

que um fogo vindo do céu

devastava a América.

O homem sonha

se deus quiser

a obra nasce. (PIMENTA, 1998) 
Réplica cáustica (arrepiantemente profética, se pensarmos que é anterior ao 11 de Setembro) ao famoso "O Infante", da Mensagem, de Pessoa, o poema é prova de como sempre foi possível a Alberto Pimenta cultivar a "persistência do riso" (BARRENO; HORTA;COSTA, 2010, p. 273), sabendo que há um tipo de riso que permite a insurreição e aponta para a necessidade da comunicação e da partilha, sejam elas a do corpo social, a do corpo individual (no espaço de desejo e do erotismo) ou a do corpo político, assim contrariando os impotentes do poder.

Dois anos depois da publicação de Marthya de Abdel Hamid, em 2007, Pimenta haveria de escrever Indulgência Plenária, um livro comovente e muito belo, onde, em tom mais críptico, mas em registo igualmente crítico, daria corpo a Gisberta, a transsexual assassinada no Porto, que sofreu sevícias e torturas inimagináveis durante mais de três dias antes de morrer às mãos de um grupo de menores com idades entre os 12 e os 16 anos, cuja pena oscilou entre os 11 e os 13 meses de internamento em centros educativos. Imigrante brasileira transsexual, sem-abrigo e seropositiva, Gisberta era uma estrangeira num país estrangeiro, também uma estranha em várias instâncias normativas. Quase não teve fotografias nos jornais. Mostrá-la seria como mostrar os iraquianos, ou os árabes em ângulos diferentes e múltiplos, significaria torná-la humana e cidadã, uma igual a "nós". O corpo de Gisberta representa esses corpos de que fala Butler (2009), e a vida de Gisberta, uma vida semelhante a essas vidas menos "pranteáveis" e socialmente descartáveis, que Butler denuncia. É fundamental, enquanto acto poético-político insistir em que corpos como o de Gisberta ou como os que surgem expostos em Marthya Abdel Hamid, são corpos continuamente esquecidos, apagados e insultados. E que esses corpos importam e são matéria, como eloquentemente Butler havia já reclamado em 1993, no seu notável, e de tão expressivo título, Bodies that Matter.

Mas o estrangeiro, ou o "outro" pode tornar-se ainda, em Marthya de Abdel Hamid, o próprio 'ocidental'; já não o muçulmano ou a transsexual, mas aqueles que, metonimicamente, são representados pelas botas ("Estes furacões / De botas / São meus semelhantes? / Falam alto de mais / Ou ladram?" (PIMENTA, 2005, p. 27)) e que cultivam não a paz, ou a calma de apurar "os aromas da vida, / O halo das pedras, / O poder das árvores, / A graça das ervas / E o nome das estrelas" ( ibid., p. 47), mas a velocidade cega da voracidade de serem continuamente impelidos a perseguir o lucro e as certezas danosas ou inúteis, impondo 
uma "vida / Que se tornou / Mais rápida, / Corroída por alarmes" (ibid., p. 11), ficando, assim, de costas para o futuro. São aqueles que "trazem o temporal / Por mandado divino" (ibid., p. 40), que têm "a pressa de um furacão / Que já perdeu muito tempo no caminho" (ibid., p. 52). São ainda aqueles cuja aprendizagem se fez a partir da interiorização da discriminação e da indiferença pela beleza, o que os torna igualmente vítimas de uma moldura social cruel e de uma socialização assente na barbárie. Por isso a marcha das botas destes invasores adultos que "v[êm] abalar" o "solo" ocupado e "continuar a pisar-lhe / O rosto" (ibid., p 17) foi-Ihes dada a conhecer e por eles experimentada com o caminhar da infância: eles "não aprenderam / A sentir a fonte / Da seiva da terra / Na planta dos pés, / Só a esmagá-la / Desde que, / Ainda crianças, / Calçaram as primeiras botinhas" (ibid., p. 16).

O outro torna-se agora não o 'oriental', mas o invasor estrangeiro e estranho, o que fala uma língua incompreensível e violenta, aquele cujas acções fazem o poeta duvidar da possibilidade de o encarar como semelhante. Porque a este estrangeiro invasor cabe só a turbulência e a confusão, a ausência de paz e de visão, ele e os iguais a ele são apresentados como "gatos pequenos / Quando / Perderam a mãe" (ibid., p. 26) - mais do que vulneráveis ou frágeis, duplamente cegos.

Sobrepondo-se ao ruído dos que caminham alheios às emoções, e "por isso têm [...] um coração / Que deve ser cego" (ibid., p. 13), ouve-se, em trovão capaz de "fender a alma", a voz que fala em nome de Abdel Hamid, e segundo Alberto Pimenta. Nessa voz se completam, Habdel e Pimenta, ambos companheiros de poesia, falando "de dentro para fora", transportando a mensagem:

Nunca porém a vida

Deixou de se reger

Pelo coração

$[\ldots]$

Esta

É a palavra

Dum coração que vê (ibid., p. 11-14) 
Dentro do mundo e das coisas do mundo, poderia acrescentar.

Por isto, e a terminar, retomo uma das epígrafes com que abri este breve ensaio e que pedi emprestada a Casas Pardas, de Maria Velho da Costa, publicado em 1977, justamente o mesmo ano em que saía a primeira edição de Orientalism, de Said. Essa epígrafe inscreve-se num excerto que faz parte da última casa, a de Elvira, a criada. É de Elvira a fala:

Eu quero dizer. Que os vossos altos edifícios e saber são lindos como o mirante de Deus. Eu quero dizer que só são belos os primores da minha rudeza se vierdes comigo ao que nela me mantém. Que não me vale ser visitada de olhos afagadeiros e saudosos de quem nunca foi. Mostra-me a tua vida e a disposição quotidiana dos teus gestos. Que limpas, que rasgas, que montas pedra sobre pedra ou literalmente despejas, quem te esfregou a roupa do corpo, que moição de rins sofres, que peso te derreia. Deleita-te e louva-me a sageza e muito complexa herança dos enfeites, alfaias, traças do costume e penas laborais, contos e ditos, mas enterra a tua fala num corpo que saiba do que dizes. E dá-me esse modo como discorres da história dos bens, da perfeição dos sentidos, dos amores lentos, da paragem dos céus e fluxo das águas com todos os seus nomes. Ah que eu possa saber de mim sabendo das coisas. (COSTA, 1996, p. 433-434)

(Pressinto que Abdel-Pimenta haveria de gostar). 


\section{Referências}

BARRENO, Maria Isabel; HORTA, Maria Teresa ; COSTA, Maria Velho de . Novas cartas portuguesas. Ed. Anotada. Coord. Ana Luísa Amaral. Lisboa: D. Quixote, 1972. ed. Anotada, , Lisboa, Dom Quixote, [1972] 2010.

BBC News Looters ransack Baghdad Museum, 2003. Disponível em: http://news.bbc. co.uk/2/hi/middle_east/2942449.stm

BRECHT, Bertold. Poems 1913-1956, eds. John Willett, Ralph Manheim, Erich Fried, Routledge. New York: Methuen, 1979.

BUTLER, Judith. Bodies that matter: In the discursive limits of sex. New York: Routledge, 1993.

BUTLER, Judith . Frames of War: When is life grievable?. London: Verso, 2009.

COSTA, Maria Velho da. Casas Pardas. Prefácio Manuel Gusmão. Lisboa: Dom Quixote, [1977] 1996.

DELEUZE, Gilles. Spinoza, philosophie pratique. Paris; Les Editions de Minuit, 2003.

ELIOT, T. S. A terra devastada. Intro. e trad. Gualter Cunha. Lisboa: Relógio D’Água, 1999. Disponível em: <http://opalcoeomundo.blogspot.pt/2010/10/alberto-pimenta-tortura-e-metafisica.html>.Acesso em: 11 de fev. 2016.

in http://news.bbc.co.uk/2/hi/middle east/2942449.stm, acesso em 11 de fev.2016.

PIMENTA, Alberto . Tortura e metafísica, entrevista,,, 2010.

PIMENTA, Alberto. Bestiário Lusitano. Lisboa: ed. de autor, 1980.

PIMENTA, Alberto . As moscas de Pégaso. Lisboa: \& etc, 1998.

PIMENTA, Alberto Marthya de Abdel Hamid segundo Alberto Pimenta. Lisboa: \& etc, 2005.

RAMALHO, Maria Irene . Interrupção poética: Um conceito pessoano para a lírica moderna. , Revista Veredas, n. 3, 2000.

RAMALHO, Maria Irene. Atlantic Poets: Fernando Pessoa's Turn in Anglo-American Modernism. Estados Unidos: University Press of New England, 2003.

RAMALHO, Maria Irene. Poetas do Atlântico: Fernando Pessoa e o Modernismo Anglo-Americano. Porto: Afrontamento, 2007.

RAMALHO, Maria Irene. E não há prodígio aqui. A propósito de De nada, de Alberto Pimenta. Jornal de Letras, n. 1108, 20 de mar.de 2013.

RAMALHO, Maria Irene; ANDRADE, Mónica Varese.Introdução, in Adrienne Rich, Uma paciência selvagem: antologia poética. introdução e tradução de Maria Irene RamaIho e Mónica Varese Andrade. Lisboa: Cotovia, p. 11-26, 2008.

$\mathrm{RICH}$, Adrienne.The dream of a common language. New York: Norton \& Norton, 1978.

RICH, Adrienne Dark fields of the epublic: Poems 1991-1995. New York: W. W. Norton, 1995. 
$\mathrm{RICH}$, Adrienne. Why I refused the national medal for the arts. Los Angeles Times, Estados Unidos, 3 de ago 1997.Disponível em: <http://articles.latimes.com/1997/ aug/03/books/bk-18828>. Acessado em: 11 fev. de 2016.

$\mathrm{RICH}$, Adrienne. A human eye. Essays on Art in Society, 1997-2008. New York: W. W. Norton, 2009.

SAID, Edward. Preface. Orientalism. London: Penguin, p. xii-xxiii, [1977] 2003.

SAID, Edward. Orientalism. London, Penguin Books, [1978] 2003.

SIMAWE, Saadi. Iraqi Poetry Today. Modern Poetry in Translation. London: Zephyr Press, n. 19, new series, Zephyr Press, 2003. 